\title{
A Rare Case of Guillain-Barré Syndrome following COVID-19 Vaccination
}

\author{
Yash Kripalani ${ }^{1}$, Vidyadhara Lakkappan ${ }^{1}$, Lipeeka Parulekar ${ }^{2}$, Anjum Shaikh ${ }^{1}$, Rakesh Singh ${ }^{3}$, Pradeep Vyas ${ }^{1}$ \\ ${ }^{1}$ Department of Critical Care Medicine, Holy Family Hospital, Bandra, Mumbai, India \\ ${ }^{2}$ Department of General Internal Medicine, Holy Family Hospital, Bandra, Mumbai, India \\ ${ }^{3}$ Department of Neurology, Holy Family Hospital, Bandra, Mumbai, India
}

Doi: 10.12890/2021_002797 - European Journal of Case Reports in Internal Medicine - @ EFIM 2021

Received: $23 / 07 / 2021$

Accepted: $13 / 08 / 2021$

Published: 14/09/2021

How to cite this article: Kripalani Y, Lakkappan V, Parulekar L, Shaikh A, Singh R, Vyas P. A rare case of Guillan-Barré syndrome following COVID-19 vaccination. EJCRIM 2021;8: doi:10.12890/2021_002797.

Conflicts of Interests: The authors declare there are no competing interests.

This article is licensed under a Commons Attribution Non-Commercial 4.0 License

\section{ABSTRACT}

Various vaccines against COVID-19 have been developed since SARS-CoV-2 emerged at the end of 2019. Their emergency administration in healthcare settings has been accompanied by numerous adverse effects. A case of Guillain-Barré syndrome following vaccination with Covishield is presented here to highlight this possible adverse condition.

\section{LEARNING POINTS}

- Guillain-Barré Syndrome (GBS) is a very rare complication after vaccination against SARS-CoV-2.

- The key concepts related to the understanding, management and outcomes of patients with GBS are discussed.

\section{KEYWORDS}

Covishield, Guillain-Barré syndrome, GBS, AstraZeneca, coronavirus, pandemic, vaccine, ChAdOx1

\section{INTRODUCTION}

Guillain-Barré syndrome (GBS) is a rare autoimmune disease which can be fatal and whose exact cause is still unknown. A very small number of people can develop GBS following vaccination. The Oxford-AstraZeneca COVID-19 vaccine is distributed under the brand name Covishield in India. It consists of a viral vector of the modified chimpanzee adenovirus ChAdOx1 with COVID-19 spikes present on the outer surface. This protein helps to generate an immune response against SARS-CoV-2. The vaccine has been approved for emergency use by the WHO.

\section{CASE DESCRIPTION}

A 52-year-old woman with no comorbidities received her first dose of the Oxford-AstraZeneca Covishield vaccine on 1 April 2021. There was no swelling, redness or pain at the site of injection. The patient developed a fever that evening which continued the following day but eventually resolved. She then complained of a mild headache which lasted for 2 days. On the ninth day after vaccination, she developed lower back pain but was able to walk comfortably. The next day she complained of extreme fatigue and on day 11 , she experienced progressive difficulty in walking and moving. She presented to the ER with bilateral lower limb weakness with pain and a burning sensation in the lower back that radiated downwards, was unable to walk without support and complained of limping. She did not have a history of nausea, vomiting, seizures, loss of consciousness, facial weakness or speech alteration. She had no autoimmune conditions, previous cerebrovascular events or cardiac events. She was able to empty her bowels and bladder comfortably. She did not complain of shortness of breath. 
On examination, she was haemodynamically stable and maintained oxygen saturation on room air. On neurological examination, she was conscious and well oriented to time, place and person. There were no memory or speech-related deficits, and soft touch and pain sensations were present in all four limbs. Muscle density and tone was normal in both upper and lower limbs with no involuntary movements. Power was reduced to $3 / 5$ in both lower limbs and to 4/5 in both upper limbs, with intact coordination in the upper limbs. Reduced deep tendon reflexes were noted as well as a diminished plantar reflex bilaterally. Cerebellar function seemed to be intact. There was no cranial nerve involvement on examination. All other systemic examinations were within normal limits.

The patient was transferred to the intensive care unit for further management. An MRI scan of the brain and entire spine was inconclusive. A Covid RT-PCR swab was negative (non-reactive) and COVID-19 spike protein neutralising antibody levels were elevated (Table 1), suggesting an immune response due to recent vaccination. We also conducted a nerve conduction study along with electromyography (EMG) which revealed mild demyelinating distal motor neuropathy in all four limbs (Table 2).

\begin{tabular}{|l|l|}
\hline Laboratory test & Result \\
\hline COVID-19 RT-PCR & Non-reactive \\
\hline COVID spike protein neutralising IgG antibody & $27.0(\mathrm{AU} / \mathrm{ml})($ positive if $\geq 15.0)$ \\
\hline
\end{tabular}

Table 1. Initial investigations

\begin{tabular}{|c|c|c|c|c|c|}
\hline Site & Latency (ms) & Duration (ms) & Amplitude (mV) & Segment & $\mathrm{NCV}(\mathrm{m} / \mathrm{s})$ \\
\hline \multicolumn{6}{|l|}{ Median left } \\
\hline Wrist & 5.1 & 6.8 & 8.2 & Wrist & - \\
\hline Elbow & 9.7 & 7.6 & 6.1 & Wrist-elbow & 47.6 \\
\hline \multicolumn{6}{|l|}{ Median right } \\
\hline Wrist & 4.0 & 6.5 & 5.3 & Wrist & - \\
\hline Elbow & 8.0 & 6.8 & 4.2 & Wrist-elbow & 54.3 \\
\hline \multicolumn{6}{|l|}{ Ulnar left } \\
\hline Wrist & 3.7 & 6.8 & 9.8 & Wrist & - \\
\hline Elbow & 8.1 & 7.6 & 10.5 & Wrist-elbow & 54.4 \\
\hline \multicolumn{6}{|l|}{ Ulnar right } \\
\hline Wrist & 3.3 & 5.1 & 8.3 & Wrist & - \\
\hline Elbow & 8.5 & 5.3 & 6.2 & Wrist-elbow & 46.3 \\
\hline \multicolumn{6}{|l|}{ Peroneal left } \\
\hline Ankle & 4.5 & 6.8 & 9.6 & Ankle & - \\
\hline Popliteal & 12.2 & 7.9 & 8.0 & Ankle-popliteal & 43.8 \\
\hline \multicolumn{6}{|l|}{ Peroneal right } \\
\hline Ankle & 4.9 & 7.3 & 7.8 & Ankle & - \\
\hline Head of fibula & 13.2 & 7.4 & 5.4 & Ankle-head of fibula & 38.5 \\
\hline \multicolumn{6}{|l|}{ Tibial left } \\
\hline Ankle & 5.7 & 7.8 & 13.5 & Ankle & - \\
\hline Head of fibula & 15.5 & 7.9 & 9.8 & Ankle-head of fibula & 36.5 \\
\hline \multicolumn{6}{|l|}{ Tibial right } \\
\hline Ankle & 5.4 & 7.2 & 10.3 & Ankle & - \\
\hline Popliteal & 15.5 & 8.5 & 7.9 & Ankle-popliteal & 36.2 \\
\hline
\end{tabular}

Table 2. Nerve conduction study 


\section{of Case Reports in \\ Internal Medicine}

We proceeded with a lumbar puncture under aseptic conditions on 15 April 2021 and sent the cerebrospinal fluid (CSF) for routine investigation and a BioFire PCR meningitis profile. CSF studies reported an elevated total protein level of $91 \mathrm{mg} / \mathrm{dl}$ and glucose of $108 \mathrm{mg} / \mathrm{dl}$ with a normal leucocyte count of 5 cells $/ \mathrm{mm}^{3}$, suggesting the polyneuropathy was likely GBS due to albuminocytological dissociation (Table 3). The BioFire meningitis panel was negative, ruling out meningitis.

\begin{tabular}{|l|l|l|}
\hline \multicolumn{2}{|l|}{ Test } & \multicolumn{2}{l}{ Value } & Normal range \\
\hline Physical examination & 7 & - \\
\hline Quantity (ml) & Colourless & Colourless \\
\hline Colour & Clear & Clear \\
\hline Appearance & Absent & Absent \\
\hline Xanthochromia & Absent & Absent \\
\hline Clot or fibrin & Absent & Absent \\
\hline Blood & \multicolumn{2}{|l|}{} \\
\hline Chemical examination & 91 & $15-45$ \\
\hline Total proteins (mg/dl) & 132 & $110-135$ \\
\hline Chlorides (mEq/l) & 108 & $50-80$ \\
\hline Sugar (mg/dl) & & - \\
\hline Microscopic examination & Absent & $<2000$ \\
\hline Red blood cells (cells/mm³) & 5 & $0-6$ \\
\hline Total WBC count (cells/mm³) & 500 & - \\
\hline Lymphocytes (\%) & \multicolumn{2}{|l|}{} \\
\hline
\end{tabular}

After appropriate consent was obtained, we began management with intravenous immunoglobulins for 5 days, resulting in no improvement. The patient's weakness progressed to $0-1 / 5$ in both lower and upper limbs. The patient was intubated and ventilated because of severe tachypnoea and a tracheostomy procedure was carried out a week later.

As of July, the patient continues to require intensive care treatment. We successfully weaned her from the ventilator and she currently does not require respiratory support and decannulation of the tracheostomy is being planned. However, there has been no significant improvement in power and the patient remains in a quadriplegic state requiring extensive rehabilitation and physiotherapy.

\section{DISCUSSION}

Guillain-Barré syndrome is a rare autoimmune condition that is usually appears after infection and results in inflammatory demyelination of nerve fibres. Previous studies conducted during the 1976 swine flu outbreak found GBS developed after vaccination, with 8.8 cases reported per million recipients of influenza vaccine ${ }^{[1]}$.

An association between the Covishield vaccine and GBS has not yet been established. The Covishield vaccine consists of a viral vector of the modified chimpanzee adenovirus ChAdOx1 with COVID-19 spikes present on the outer surface ${ }^{[2]}$. It is delivered in two doses 4-12 weeks apart ${ }^{[3]}$. Between April 2020 and December 2020, more than 20,000 individuals participated in clinical trials in the UK, Brazil and South Africa. The results overall concluded that the vaccine was approximately $76 \%$ effective in protecting against SARS-CoV-2 and produced an appropriate immune response to prevent hospitalisation and death 22 days after administration of the first dose ${ }^{[2]}$.

A few case reports have been published describing patient who developed GBS within 2 weeks of vaccination. A quick search on PubMed with the keywords 'GBS' and 'vaccine' revealed two publications. A case report by Nasuelli et al. reported the case of a 59-year-old man who developed four-limb distal paraesthesia and postural instability 10 days after vaccination with ChAdOx1 nCoV-19, which is a component of 
Covishield. The patient was diagnosed with demyelinating polyradiculoneuropathy on EMG ${ }^{[4]}$.

Another case report published by Maramattom et al. discussed seven patients who developed neurological deficits within 2 weeks of vaccination. All patients were 43-70 years of age, six were female and one was male. Six patients progressed to respiratory failure. It was also reported that one recovered, while others were still hospitalized. All patients progressed to areflexic quadriplegia and four patients developed other cranial neuropathy. It is also worth noting that the authors reported a 1.4-10-fold higher number of cases of GBS than expected in the studied population ${ }^{[5]}$. Eight case reports comprising 14 patients published in PubMed-indexed journals describe GBS after vaccination $^{[4-11]}$. Four of these patients developed GBS after receiving an mRNA-based vaccine (Pfizer) ${ }^{[8-11]}$ and 10 after a ChAdOx1-based vaccine (AstraZeneca) ${ }^{[4-7]}$. Only a few of the millions of vaccinated patients have developed GBS, indicating that this neurological adverse effect is extremely rare.

\section{CONCLUSION}

The COVID-19 pandemic has caused major economic problems and huge loss of life. Vaccination is the best way to prevent hospitalisation and death. Oxford and AstraZeneca together have developed Covishield, which showed promising results during clinical trials in reducing the severity of COVID-19 infection ${ }^{[2,3]}$. However, the vaccine does have some adverse effects, including the very rare risk of developing GBS. Nevertheless, the benefits of this vaccine clearly outweigh the risks. Further study of GBS developing after vaccination may be required. This case report aims to highlight the importance of vigilance for GBS and the initiation of prompt investigation and treatment when patients present with such neurological symptoms following vaccination.

\section{REFERENCES}

1. Vellozzi C, Iqbal S, Broder K. Guillain-Barré syndrome, influenza, and influenza vaccination: the epidemiologic evidence. Clin Infect Dis 2014;58(8):1149-1155. doi: 10.1093/ cid/ciu005. PMID: 24415636.

2. Voysey M, Clemens SAC, Madhi SA, Weckx LY, Folegatti PM, Aley PK, et al. Safety and efficacy of the ChAdOx1 nCoV-19 vaccine (AZD1222) against SARS-CoV-2: an interim analysis of four randomised controlled trials in Brazil, South Africa, and the UK [published correction appears in Lancet 2021;397(10269):98]. Lancet 2021;397(10269):99111. doi: 10.1016/S0140-6736(20)32661-1

3. Barrett JR, Belij-Rammerstorfer S, Dold C, Ewer KJ, Folegatti PM, Gilbride C, et al. Phase 1/2 trial of SARS-CoV-2 vaccine ChAdOx1 nCoV-19 with a booster dose induces multifunctional antibody responses [published correction appears in Nat Med 2021;27(6):1113]. Nat Med 2021;27(2):279-288. doi: 10.1038/s41591-020-01179-4

4. Nasuelli NA, De Marchi F, Cecchin M, De Paoli I, Onorato S, Pettinaroli R, et al. A case of acute demyelinating polyradiculoneuropathy with bilateral facial palsy after ChAdOx1 nCoV-19 vaccine. Neurol Sci 2021 Jul 17:1-3. doi: 10.1007/s10072-021-05467-w. Online ahead of print. PMID: 34272622; PMCID: PMC8285283.

5. Maramattom BV, Krishnan P, Paul R, Padmanabhan S, Cherukudal Vishnu Nampoothiri S, Syed AA, et al. Guillain-Barré syndrome following ChAdOx1-S/nCoV-19 vaccine. Ann Neurol 2021;90(2):312-314. doi: 10.1002/ana.26143. PMID: 34114256.

6. McKean N, Chircop C. Guillain-Barré syndrome after COVID-19 vaccination. BMJ Case Rep 2021;14(7):e244125. doi: 10.1136/bcr-2021-244125. PMID: 34330729.

7. Hasan T, Khan M, Khan F, Hamza G. Case of Guillain-Barré syndrome following COVID-19 vaccine. BMJ Case Rep 2021;14:e243629.

8. Razok A, Shams A, Almeer A, Zahid M. Post-COVID-19 vaccine Guillain-Barré syndrome; first reported case from Qatar. Ann Med Surg (Lond) 2021;67:102540. doi: 10.1016/j. amsu.2021.102540. PMID: 34249353; PMCID: PMC8253659.

9. Waheed S, Bayas A, Hindi F, Rizvi Z, Espinosa PS. Neurological complications of COVID-19: Guillain-Barre syndrome following Pfizer COVID-19 vaccine. Cureus 2021;13(2):e13426. doi: 10.7759/cureus.13426. PMID: 33758714; PMCID: PMC7978140.

10. Trimboli M, Zoleo P, Arabia G, Gambardella A. Guillain-Barré syndrome following BNT162b2 COVID-19 vaccine. Neurol Sci 2021 Aug 4:1-2. doi: 10.1007/s10072-02105523-5. Online ahead of print. PMID: 34346014; PMCID: PMC8331323.

11. Finsterer J. Exacerbating Guillain-Barré syndrome eight days after vector-based COVID-19 vaccination. Case Rep Infect Dis 2021;2021:3619131. doi: 10.1155/2021/3619131 PMID: 34055430; PMCID: PMC8123983. 